\title{
Analysis of Disputes in Transportation Projects
}

\author{
M. Emre Bayraktar \\ Associate Professor, OHL School of Construction, Florida International University, \\ 10555 West Flagler Street, EC 2953 \\ Miami, FL 33174, USA \\ bayrakm@fiu.edu \\ Cagri Cinkilic \\ Former Graduate Student, OHL School of Construction, Florida International University \\ 10555 West Flagler Street, EC 2900 \\ Miami, FL 33174, USA \\ ccink001@fiu.edu \\ Farrukh Arif* \\ Ph.D. Candidate, OHL School of Construction, Florida International University, \\ 10555 West Flagler Street, EC 2946 \\ Miami, FL 33174, USA \\ *farif001@fiu.edu \\ Received 29 May 2012 \\ Accepted 24 August 2012
}

\begin{abstract}
Disputes in construction projects are fairly common. They most often lead to increased costs, delays, and damaged business relationships. Disputes can also result in loss of reputation, personnel resources, and potential business opportunities. Previous studies have shown that the frequency of disputes in construction projects can be reduced through the timely identification of potential dispute sources and the implementation of effective lessons-learned strategies. This paper presents an analysis of the disputes for transportation projects in the state of Florida and the related lessons-learned in order to prevent these disputes from recurring in future projects. Two hundred and sixtytwo (262) cases of disputes in transportation projects between 1994 and 2008 stored in the Dispute Resolution Board (DRB) database of the Florida Department of Transportation (FDOT) were analyzed. It was found that majority of disputes were due to unforeseen conditions. Also, more than half of the disputes (58\%) occurred during the main construction stage of the projects. Most of the lessons-learned were derived from the evaluation of the DRB reports aimed to address ambiguous specifications, a responsibility-assignment mechanism, and poor conceptual planning.
\end{abstract}

Keywords: dispute, lessons learned, transportation projects, dispute resolution board.

\section{Introduction}

The construction business appears to be one of the most problematic as opposing ideas may lead to disputes in projects. This is a result of the risks and complexities inherent to the nature of construction projects, as well as the divergent interests of the parties involved; as such, disputes are often an unavoidable consequence of the * Corresponding Author construction process (Levin 1998). Disputes during construction projects are counterproductive to the progress of the project. A dispute takes place when there is a disagreement regarding the understanding and application of the contract (Hibberd and Newman 1999). Disputes in construction projects may be financial, legal, or take on other forms. They often lead to loss of finances, time, and market share. Not only that, but 
disputes can also result in a loss of reputation. However, previous studies have shown that the frequency of disputes on construction projects can be reduced through the proper identification of the dispute and an effective lessons-learned mechanism (Groton 1997, Mitropoulos and Howell 2001). In the case of transportation projects, these lessons-learned can be applied at different stages of the project in a variety of ways; such processes are helpful for dealing with issues at the local, regional, state, and national levels.

This paper analyzes and evaluates the disputes in transportation projects in Florida and presents a lessonslearned document. First, the sources of disputes in construction and use of a lessons-learned approach to dispute resolution is examined in the literature review. Then, a close examination and analysis of disputes reported in the Dispute Resolution Board (DRB) database of the Florida Department of Transportation (FDOT) is conducted. It is hoped that this paper will provide a document that, if needed, can be used throughout the entire sequence of transportation decision-making, from transportation planning to project development to prevent future disputes.

\section{Effectiveness of Dispute Resolution Boards}

A DRB is a board of impartial professionals formed at the beginning of a project to follow construction progress, and is available on short notice to resolve disputes for the duration of the project. Usually, a DRB consists of three members selected jointly by the contractor(s) and owner, to monitor the progress of construction works, and to recommend a resolution for disputes in a timely fashion. DRB members are generally familiar with the type of construction involved, are respected in the industry, and approach their responsibilities with neutrality and impartiality (ElAdaway 2007). It is found that the DRB process is more successful than any other alternative technique for dispute resolution in construction disputes. The success rate is very high, $98 \%$ until 2007, in resolving disputes without appealing to litigation (DRB Manual 2007).

Since the first successful implementation in 1975, DRBs have gained popularity as a standing neutral Alternative Dispute Resolution (ADR) technique. Menassa (2010) reports that DRBs have been successfully implemented in all construction sectors in the United States. The effectiveness of DRBs as a prevention technique was observed in approximately
$50 \%$ of the 810 projects in which no disputes were ever heard through a DRB formal hearing. For the remaining $50 \%$ of the projects, the effectiveness of DRB as an ADR technique was found to exceed $90 \%$ when comparing the number of disputes that were settled due to DRB recommendation to those that were actually heard during a DRB session.

With the efficacy of DRBs as discussed above in mind, a lessons-learned approach can be applied to get the highest future benefits from the case histories of previous disputes resolved through the DRBs. For this purpose, the DRB database of the Florida Department of Transportation has been utilized herein.

\section{Lessons-Learned Approach for Dispute Resolution}

Throughout the construction of any facility, knowledge is obtained and lessons are learned from both positive and negative experiences. Harrison (2003) defines lessons learned as "a good work practice or innovative approach that is captured and shared to promote repeat application, or an adverse work practice or experience that is captured and shared to avoid recurrence." The lessons-learned process includes three key steps: collection, analysis, and implementation (Caldas et al. 2009).

Many organizations in the construction industry have come to recognize the importance of a lessonslearned program (LLP) as a vital asset in knowledge management systems. In these organizations, project team members generally acquire new knowledge as their careers progress. This knowledge, which includes both the successes that organizations want to repeat and the problems that they wish to prevent, may not be routinely disseminated. The benefits to be gleaned from, the optimized dissemination of such knowledge highlights the importance of LLP (Caldas et al. 2009).

In the field of transportation, the data that would be required to develop meaningful lessons-learned from claims are typically available in the Dispute Resolution Board (DRB) database. There are, however, some barriers that prevent effective implementation of lessons-learned. These barriers are as follows: (i) the lesson is too general to be passed from one case to another, (ii) the lesson is ambiguous, not mutually exclusive, and collectively exhaustive to implement, (iii) the lesson is not typically linked to the project stage, (iv) lacks a meaningful classification system, (v) has 
difficulty in integrating new systems into existing procedures and operations, (vi) has an unmanageable format that limits the access, retrieval, and updating of a potentially enormous volume of lessons, etc. (Marlin 2008).

On the other hand, lessons-learned provide many benefits if used effectively. Lessons-learned allow other practitioners to learn from previous experiences and avoid "reinventing the wheel". They help stakeholders at different levels to understand the relevance of other activities and achievements, thus improving collaboration and coordination. Moreover, lessons inform decision-makers about common mistakes and assist in the facilitation of a more efficient working environment.

\section{Research Scope and Objectives}

In order for a lessons-learned document to be successful, it must have a clear "application domain". The purpose of this paper is to identify, analyze, and evaluate the current dispute reports in the FDOT DRB database for the development of such a document with a focus on transportation projects. To this end, 262 reports in the FDOT DRB database from between 1994 and 2008 were reviewed against the above criteria

\section{Research Methodology}

In the first step of this research, a thorough literature review was conducted (Fig. 1). Its purpose was to determine the construction dispute resolution strategies most effective in the United States for the development of a lessons-learned approach. As demonstrated in the literature, the DBR approach has consistently proven successful. Another purpose was to determine the criteria required to produce a quality lessons-learned document; various sources such as academic journals, technical reports, news articles, and online resources were used in this regard. In the second step, a quantitative analysis was performed to determine the basic characteristics of the 262 disputes in the FDOT DRB database, such as number of disputes, time value of disputes, monetary value of disputes, and dispute results. In the third step, disputes were categorized by contractual aspect and construction stage. Finally, a qualitative and critical analysis was carried out to develop a lessons-learned document for the various disputes that may occur in transportation projects. Also, conclusions were made and recommendations put forward.

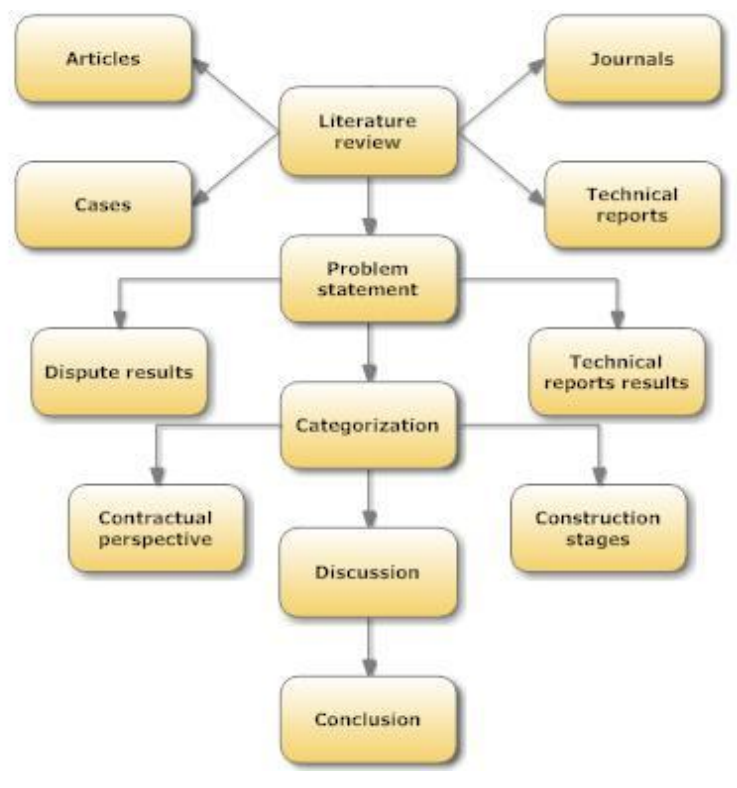

Fig. 1. Research Methodology.

\section{Analysis and Discussions}

Two hundred and sixty--two (262) reports stored in the FDOT DRB database and containing dispute information between 1994 and 2008 were reviewed. All of the disputes submitted by the contractors to the DRB were resolved, except one. The reports were quantitatively analyzed to determine the general characteristics of the disputes and to categorize disputes both by contractual aspect and construction stage. The analysis and a discussion thereof are presented in the following sections.

\subsection{General Characteristics of Disputes}

Out of the 262 disputes, the contractors won 119 (45.42\%) times, while FDOT won 133 (50.76\%). In addition to these numbers, 10 of the disputes (3.82\%) were concluded in negotiation. Fig. 2 shows information about the disputes in terms of monetary and time values. As far as the monetary value of the disputes is concerned, the majority of disputes, i.e. 188 disputes (72\%), did not have any monetary value specified. Out of the remaining 74 disputes, 39 disputes were in the range of $\$ 0$ to $\$ 49,999,13$ disputes were in the range of $\$ 50,000$ to $\$ 99,999,7$ disputes were in the range of 
$\$ 100,000$ to $\$ 149,000$, and the remaining 15 disputes were $\$ 150,000$ and above. Regarding time value, the records showed that 185 of the disputes $(71 \%)$ did not have this characteristic specified. Out of the remaining 77 disputes, 43 had a time value of 0 to 25 days, 9 disputes had a value of 26- to 50 days, 12 disputes had a value of 51 to 75 days, and the remaining 13 disputes had a time value of above 76 days.

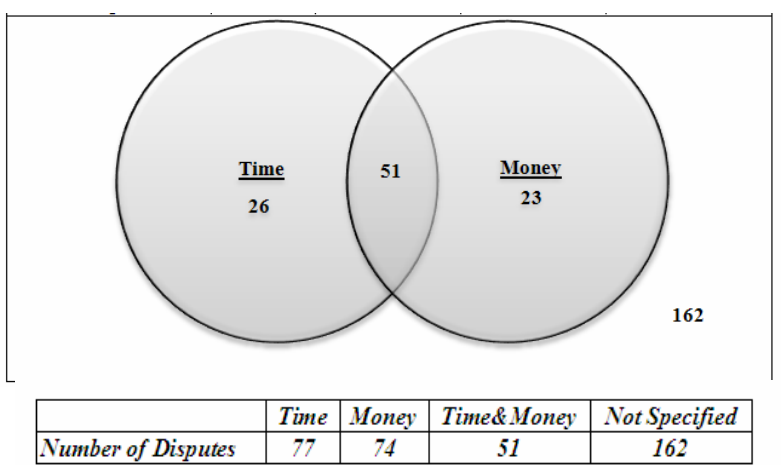

Fig. 2. Disputes in Terms of Monetary and Time Values

\subsection{Categorization of Disputes by Contractual Aspect}

Ten categories of disputes, as per contractual aspects were defined through an extensive literature review. These categories included material, quality, safety, plans and specifications, construction methods, equipment, third party hindrances, quantity variation, unforeseen conditions, and permits. The 262 disputes were then cataloged under these respective aspects. Table 1 shows the number of disputes generated with respect to the different contractual aspects.

Table 1. Number of Disputes by Contractual Aspect

\begin{tabular}{lc}
\hline Category & Number of Disputes \\
\hline Material & 32 \\
Quality & 3 \\
Safety & 4 \\
Plans \& Specifications & 43 \\
Construction Methods & 22 \\
Equipment & 2 \\
Third Party Hindrance & 21 \\
Quantity Variation & 58 \\
Unforeseen Conditions & 67 \\
Permit & 10 \\
\hline \multicolumn{2}{c}{ TOTAL } \\
\hline
\end{tabular}

As shown in Table 1, 67 of the disputes (26\%) occurred due to unforeseen conditions. Quantity variation is the second most encountered dispute characteristic, with 58 disputes (22\%), while the third leading characteristic is plans and specifications with 43 disputes (16\%).

\subsection{Categorization of Disputes by Construction Stage}

Through an extensive literature search, six typical project stages in transportation and their subcategories were identified. The six main categories included 1) Permit, 2) Site Work, 3) Foundation, 4) Main Construction, 5) Landscaping, and 6) Other were. Fig. 3 shows the distribution of disputes in FDOT projects among these six main stages. It was found that more than half of the disputes occurred during the Main Construction stage. The Foundation stage was found to be the second most critical stage for the occurrence of disputes.

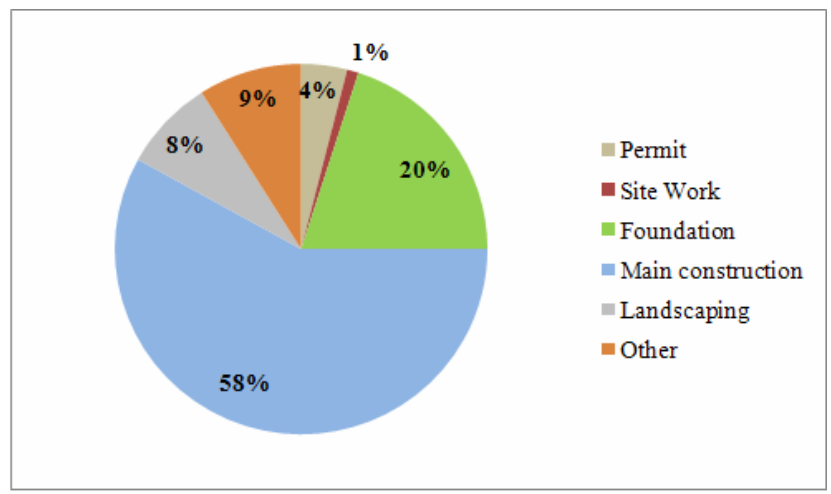

Fig. 3. Disputes in Different Construction Stages

The detailed categorization of disputes according to subcategories is shown in Table 2. Most of the disputes in the Permit stage were related to Environmental Permit Issues (50\%), while in the Foundation stage, Sheet Pile (23\%), Bridge Joints (15\%), and Additional Unforeseen Condition (12\%) -related issues occurred more frequently. During the Main Construction stage, Additional Unforeseen Condition (17\%), Utility conflicts (8\%), and Concrete/Slab/Asphalt (8\%) -related issues were found to cause disputes. In the Landscaping stage, Driveways (30\%), Sod Installation, Seeding, Fertilizing, Mulching, Mowing (30\%), and Additional Unforeseen Condition (30\%) -related issues were the contributing factors. Other than this, Delay (33\%) problems were also a significant cause of disputes. 
Table 2. Detailed Categorization of Disputes

\begin{tabular}{|c|c|}
\hline Category & $\begin{array}{c}\text { No of } \\
\text { Disputes }\end{array}$ \\
\hline \multicolumn{2}{|l|}{ Permit } \\
\hline Environmental Permit & 5 \\
\hline Lane Closure & 3 \\
\hline Site Access & 1 \\
\hline Other & 1 \\
\hline \multicolumn{2}{|l|}{ Site Work } \\
\hline Fence & 3 \\
\hline \multicolumn{2}{|l|}{ Foundation } \\
\hline Defective Specifications/Plan & 3 \\
\hline Base Material/Other & 8 \\
\hline Base Material/Shortage & 3 \\
\hline Earth Wall & 4 \\
\hline Footing (Replacement) & 1 \\
\hline Footing (Shaft) & 2 \\
\hline Sheet Pile & 12 \\
\hline Excavation & 4 \\
\hline Bridge Joints & 8 \\
\hline Additional Unforeseen Condition & 6 \\
\hline Hauling & 1 \\
\hline \multicolumn{2}{|l|}{ Construction } \\
\hline Concrete Work & 9 \\
\hline Concrete/Asphalt/Slab & 12 \\
\hline Truncated Domes & 2 \\
\hline Utility Work & \\
\hline Electrical Rough-in & 8 \\
\hline Water Rough-in & 7 \\
\hline Specialty Rough-ins (Phone) & 1 \\
\hline Specialty Rough-ins (Cable) & 2 \\
\hline Gas Utility & 2 \\
\hline Relocation & 3 \\
\hline Conflict & 13 \\
\hline Drainage Utility/Sanitary & \\
\hline Sewer Utility & 9 \\
\hline Insulation(Coating) & 5 \\
\hline Material & \\
\hline Unsuitable Material & 3 \\
\hline Extra & 3 \\
\hline Shortage & 3 \\
\hline Traffic Signals & 5 \\
\hline Repair/Replace & 2 \\
\hline Restriction & 1 \\
\hline Bridge Deck & 1 \\
\hline Defective Specifications/Plan & 3 \\
\hline Control of Work & 2 \\
\hline Maintenance of Traffic & 7 \\
\hline Additional Unforeseen Work & 26 \\
\hline Equipment (Idle) & 1 \\
\hline Equipment (Other) & 4 \\
\hline Tests & 2 \\
\hline Noise Ordinance Suspension & 1 \\
\hline Changed Site Conditions & 8 \\
\hline Non-payment & 4 \\
\hline Workman Compensation Cost & 2 \\
\hline Landscaping & \\
\hline Driveways & 6 \\
\hline Sod Installation, Seeding, Fertilizing, & 6 \\
\hline
\end{tabular}

\begin{tabular}{ll} 
Pond & 1 \\
Other & 1 \\
Additional Unforeseen & 6 \\
\hline Other & 1 \\
\hline Speciality Engineer & 2 \\
Contractual Document & 1 \\
Change in Scope of Work & 8 \\
Delay & 1 \\
Fire Hydrant & 1 \\
Discharge of Superintendant & 1 \\
Overhead Expense & 1 \\
Liquated Damage & 1 \\
Incentive-disincentive & 1 \\
Stand-by Cost of Crew & 1 \\
Off-duty Law Enforcement & 1 \\
Traffic Accident & 1 \\
Bridge Clearance & 1 \\
Schedule Interpretation & 1 \\
Vandalism/Stolen & 1 \\
Changed Market Price &
\end{tabular}

\section{Lessons-Learned and Lessons-Learned Matrix}

The lessons-learned developed from the FDOT DRB reports are presented in this section. These lessonslearned are mainly aimed at avoiding future disputes. They were derived through an intense critical analysis of the reported cases, a thorough literature review, expert opinion of the construction industry, monitoring, evaluation, and documentation techniques. It aims at building a strong foundation of knowledge and its objective is to serve as an important input, not only for dispute resolution, but also during the conceptual and detailed planning stages of transportation projects. The data were collected for the maximum benefit of users and coded as L1, L2, ...., L24 in the lessons-learned matrix, which is explained later in the text. Based on this, a lessons-learned matrix for the FDOT projects was developed (Table 3).

L1. Make sure to procure all environmental permits required by federal, state, county, and local regulatory agencies.

L2. Make sure to procure the proper water permits to cover all necessary project work on site.

L3. Proper access to the site shall be arranged.

L4. FDOT shall clearly define any restrictions before the time of bidding and changes shall only be made if FDOT is willing to provide compensation.

L5. Any change in site clearance work or fencing work characteristics shall be clearly delineated. The effect shall be determined both in terms of materials and the nature of work. 
Table 3: Lessons-Learned Matrix for FDOT Projects

\begin{tabular}{|c|c|c|c|c|c|c|c|c|}
\hline \multirow[b]{2}{*}{ Lesson } & \multicolumn{2}{|c|}{ Responsibility } & \multicolumn{6}{|c|}{ Applicability for the Avoidance of Disputes in Different Construction Stages } \\
\hline & FDOT & Contractor & Permit & $\begin{array}{c}\text { Site } \\
\text { Work }\end{array}$ & Foundation & $\begin{array}{c}\text { Main } \\
\text { Construction }\end{array}$ & Landscaping & Others \\
\hline L1 & $\mathrm{X}$ & $\mathrm{X}$ & $\mathrm{X}$ & $\mathrm{X}$ & $\mathrm{X}$ & $\mathrm{X}$ & $\mathrm{X}$ & -- \\
\hline L2 & $\mathrm{X}$ & -- & $\mathrm{X}$ & $\mathrm{X}$ & $\mathrm{X}$ & $\mathrm{X}$ & $\mathrm{x}$ & -- \\
\hline L3 & $\mathrm{X}$ & -- & -- & $\mathrm{X}$ & -- & -- & -- & -- \\
\hline L4 & $\mathrm{X}$ & $\mathrm{X}$ & $\mathrm{X}$ & $\mathrm{X}$ & $\mathrm{X}$ & $\mathrm{X}$ & -- & -- \\
\hline L5 & -- & $\mathrm{X}$ & -- & $X$ & -- & -- & -- & -- \\
\hline L6 & $X$ & -- & -- & -- & $X$ & $X$ & -- & -- \\
\hline L7 & $X$ & -- & -- & -- & $X$ & -- & -- & -- \\
\hline L8 & $\mathrm{X}$ & -- & -- & -- & $\mathrm{X}$ & -- & -- & -- \\
\hline L9 & $X$ & $\mathrm{X}$ & -- & -- & $\mathrm{X}$ & $\mathrm{X}$ & $X$ & -- \\
\hline L10 & $X$ & -- & -- & -- & -- & $X$ & -- & -- \\
\hline L11 & $X$ & $X$ & -- & -- & -- & $\mathrm{X}$ & -- & -- \\
\hline L12 & $X$ & -- & -- & -- & $X$ & $X$ & $\mathrm{X}$ & $\mathrm{X}$ \\
\hline L13 & $X$ & -- & -- & -- & $X$ & $X$ & -- & -- \\
\hline L14 & $X$ & -- & -- & -- & $X$ & $\mathrm{X}$ & -- & -- \\
\hline L15 & -- & $X$ & -- & -- & $X$ & $\mathrm{X}$ & $\mathrm{X}$ & -- \\
\hline L16 & -- & $X$ & -- & $X$ & $X$ & $\mathrm{X}$ & $\mathrm{X}$ & -- \\
\hline L17 & $\mathrm{X}$ & -- & -- & -- & $\mathrm{X}$ & $\mathrm{X}$ & $\mathrm{x}$ & -- \\
\hline L18 & $\mathrm{X}$ & -- & -- & -- & -- & $\mathrm{X}$ & -- & -- \\
\hline L19 & -- & $\mathrm{X}$ & -- & -- & -- & $\mathrm{X}$ & -- & -- \\
\hline L20 & $\mathrm{X}$ & -- & -- & -- & $\mathrm{X}$ & $\mathrm{X}$ & $\mathrm{X}$ & -- \\
\hline L21 & $\mathrm{X}$ & $\mathrm{X}$ & -- & $\mathrm{X}$ & $\mathrm{X}$ & $\mathrm{X}$ & -- & -- \\
\hline L22 & $\mathrm{X}$ & -- & -- & -- & -- & -- & $\mathrm{x}$ & -- \\
\hline L23 & $X$ & $X$ & $X$ & $X$ & $X$ & $X$ & $X$ & $X$ \\
\hline L24 & $X$ & $X$ & -- & $\mathrm{X}$ & $X$ & $\mathrm{X}$ & $\mathrm{X}$ & $\mathrm{X}$ \\
\hline
\end{tabular}

L6. To avoid defective specifications, FDOT experts should have multiple early site visits before defining the specifications. Also, other regulatory agencies shall be taken in confidence regarding the specifications and shall be involved in such visits. This exercise will prove to be extremely valuable from a cost estimation perspective as well.

L7.Site surveys and tests related to geotechnical conditions of the site shall also be performed.

L8. Foundation drawings shall provide clear and complete details to avoid any disputes.

L9. Clear instruction shall be given to contractor(s) to prevent the flow of turbid water into the canals. Contractor(s) shall also submit a notice of intent for any extra work he/she has planned in this regard.

L10. The responsibility of repair work during the construction shall be properly communicated to the contractor(s)
L11. Specifications shall clearly mention that materials proposed by the contractor(s) must be submitted in samples and approved by FDOT.

L12. There shall be no unnecessary delays in payment from FDOT once its specifications have been met and the quality of work approved.

L13.The contract shall mention any temporary arrangements required, such as a glare screen or temporary barrier wall. The documents drawn shall also address payment issues for these arrangements.

L14. The contract shall clearly address the responsibility for any unforeseen conditions. It shall also address the payment issues for such conditions.

L15. Contractor(s) shall try to anticipate any delay in advance, and shall also apply for any time extension in advance.

L16. Any problem encountered by the contractor(s) at site shall be communicated to FDOT immediately. This will expedite the compensation process if required. 
L17. Non-working days shall be clearly communicated in the contract. It shall also mention the rate of pay and other details regarding payment if these days are utilized during the construction stage.

L18. Any restrictions related to burning operations shall be mentioned in the contract.

L19. Lump sum items shall be clearly calculated with market trends in mind.

L20. Any change in scope shall be communicated to all parties in writing.

L21. FDOT is responsible for providing an alternative traffic control plan. Any changes in the plan by the contractor(s) due to prevailing conditions shall be properly communicated to all parties in writing.

L22. FDOT shall contractually bind the contractor(s) to maintain the sodden areas in a satisfactory condition until final acceptance of the project.

L23. Communication among the parties shall always be formal, in accord with contract terms and conditions. This will avoid any misinterpretation of the responsibilities, scope, and standards of the project.

L24. It shall be clearly outlined in the contract that the primary responsibility for any accident on-site lies with the contractor(s), except in case of special circumstances.

This matrix defines two things: first, the actions suggested by the lessons-learned to avoid disputes between FDOT and the contractor(s); second, it also defines the applicability of the lessons for avoiding disputes at various construction stages of the project. For instance, for the first lesson-learned (L1), the matrix in Table 4 shows that the procurement of all environmental permits required by federal state, county, and local regulatory agencies is the joint responsibility of both the FDOT and the contractor(s). This means that these stakeholders must work cooperatively to obtain the permits, in contrast to previous cases in which one blamed the other when problems occurred; hence, the resulting disputes cost the project both in terms of time and money. The applicability of these lessons-learned, then, is to avoid the disputes which are present in almost all construction stages.

\section{Conclusions and Recommendations}

Two hundred and sixty two (262) disputes in FDOT between 1994 and 2008 were analyzed. The contractors won 119 (45.42\%) times, while FDOT won 133
(50.76\%). In addition to these numbers, 10 of the disputes (3.82\%) were concluded in negotiation. Furthermore, the disputes were categorized from a contractual perspective and according to construction stages. It was found that 67 disputes (26\%) were due to unforeseen conditions. The reason behind this is that the language of the contract is for the most part unrelated to the actual costs borne by FDOT and the contractors. According to the construction stages, it was found that more than half of the disputes in Florida's transportation projects occurred during the main construction stage. This is because during the main construction stage, contractor(s) begin to enact their ideas, which may lead to various unforeseen conditions and utility transferrelated conflicts. In answer to these issues, this study has presented many recommendations regarding lessons-learned. These lessons-learned aim to avoid disputes while keeping in mind both the contractual perspective and different construction stages. Most of the lessons-learned indicate that the majority of disputes were a result of ambiguous specifications, weak responsibility-assignment mechanism, and poor conceptual planning. Therefore, a lessons-learned matrix has also been developed to assign the responsibility clearly and apply the aforementioned lessons. This matrix is also suggested to maintain a more formalized record of lessons-learned for FDOT projects. Continued improvement to this lesson-learned matrix will benefit future transportation projects, and inclusion of these lessons-learned in the conceptual and detailed planning stages can save both time and money. Furthermore, it is recommended that this study be extended to update and measure the effectiveness of the lessons-learned and presented herein.

\section{Acknowledgement}

The authors would like to thank the Florida Department of Transportation for providing data for this research.

\section{References}

1. Levin, P. (1998). "Construction contracts, claims, and disputes”, ASCE, Reston, Va. Mark

2. Hibberd, Peter R., and Paul Newman (1999), "ADR and adjudication in construction disputes". Blackwell Science Publisher.

3. Groton, J. P. (1997). "Alternative dispute resolution in the construction industry." Dispute Resolution Journal, Summer, 49-57. 
4. Mitropoulos, P., Howell, G. (2001), "Model for understanding, preventing, and resolving project disputes." Journal of Construction Engineering and Management, Volume 127 Issue 3, pp.223-233.

5. El-Adaway, Islam H., and A. Samer Ezeldin (2007), "Dispute review boards: Expected application on Egyptian large-scale construction projects.” Journal of Professional Issues in Engineering Education and Practice, Volume 133 Issue 4, pp.365-372

6. Menassa, Carol C., and Feniosky Peña Mora (2010). "Analysis of dispute review boards application in U.S. construction projects from 1975 to 2007." Journal of Management in Engineering, Volume 26, Issue 2, pp. 6577.

7. Harrison, W. (2003). “A software engineering lessons learned repository”. Proceedings of 27th Annual NASA Goddard/IEEE Software Engineering Workshop, Institute of Electrical and Electronics Engineers, Los Alamitos, CA.

8. Caldas, Carlos H., G. Edward Gibson, Jr., Runi Weerasooriya, and Angela M. Yohe (2009), "Identification of effective management practices and technologies for lessons learned programs in the construction industry." Journal of Construction Engineering and Management, Vol. 135, No. 6, pp. 531539.

9. Marlin (2008), "Implementing effective lessons learned process in a global project environment.” Published as a part of UTD 2nd Annual Project Management Symposium Proceedings. Dallas, Texas. 